\title{
Çocuk Kitaplarında Neolojizm Örneği: Buyrultulamak
}

\author{
Zeliha TUĞUZ ${ }^{*}$ (1)
}

Gönderilme Tarihi:18 Aralık 2021

Kabul Tarihi: 30 Aralık 2021

DOI: $10.52974 /$ jena. 1038220

\section{$\ddot{O} z:$}

Zihinsel etkinliklerin baskın olduğu davranışların kodlandı̆̆ bilişsel alana giren dil ögreniminde, çocuk kitapları en etkili araçlardan biridir. Çocuğun dünyayı ve çevresindeki olayları anlamaya yönelik yürüttüğ̈̈ zihinsel faaliyetlerinde, dış çevreden algılanan uyaranların önceki bilgilerle karşılaştırma ve yeni bilgiler oluşturma sürecinde, kitapların önemi yadsınamayacak düzeydedir. Duyuşsal alan kapsamına giren; insana kazandırllmak istenen duygular, tercihler, değerler, ahlaki kurallar, istekler, güdüler ve yönelimler gibi kavramların ediniminde yine akla ilk gelen kitaplardır. Söz konusu kitaplarda yeni sözcük veya deyimlerin kullanması ve bu kullanımın çocukların dil gelişimine olan katkısını ortaya koymak amacıla bu çalışmada bir çocuk yazını ürünü olan Ayla Kutlu'nun "Huvava İlk Çevre Koruyucusu”" adlı eserinin söz varlığ ögeleri araştırılmıştır. Nitel araştırma yöntemlerinden metin analizi yöntemi kullanılan çalışmanın örneklemi olan "Huvava İlk Çevre Koruyucusu”, yansız (random) olarak seçilmiştir. Yaş gözetmeksizin içinde yaşadı̆̆ı dünyaya karşı sorumlu olan belleklere çevre bilincini aşılamayı amaçlayan ve "bir karşı destan" niteliği taşıyan bu kitapta geçen ve sözlüklerde yer almadı̆̆ tespit edilen buyrultulamak sözcüğ̈̈nün neolojik değerlendirilmesi yapılmıştır. Ölçünlü dilin sözlüğüne aday olabilecek nitelikte ve zengin bir ifade gücüne sahip buyultulamak sözcüğ̈̈ buyurmak gibi sadece "emretmek" anlamıyla değil, "kendisine emredildiği üzere bildirmek" anlamılla bağlam takibi istemeyen, yazarın özgünlüğünü gösteren taze bir yaratımla çocuk yazınında yer almıştır. Bu yeni sözcükten yola çıkılarak çocuk yazınında neolojinin yeri ve işlevselliği tartışılmıştır.

Anahtar Kelimeler: Çocuk kitapları, Ayla Kutlu, Huvava, neolojizm, buyrultulamak.

\begin{abstract}
:
Children's books are one of the most effective tools in language learning, which contains the cognitive area in which behaviors dominated by mental activities are coded. The importance of books is undeniable in children's mental activities to understand the world and the events around them, in the process of comparing stimuli perceived from the external environment with previous information and creating new information. They are the first books that come to mind in the acquisition of concepts such as emotions, preferences, values, moral rules, wishes, motives and orientations that are desired to be gained by human beings, which are within the scope of the affective behaviors. In order to reveal the use of new words or phrases in children's books and the contribution of
\end{abstract}

Atıf:

Tuğuz, Z. (2021) Çocuk kitaplarında neolojizm örneği: Buyrultulamak. International Journal of Education and New Approaches, 4(2), 176-182. https://doi.org/10.52974/jena.1038220

\footnotetext{
${ }^{1}$ Mersin University, Turkey. Orcid ID: 0000-0003-0977-8858

*Corresponding Author: zelihatuguz@gmail.com
} 
this usege to the language development of children, in this study, the vocabulary elements of Ayla Kutlu's "Huvava First Environment Protector", a product of children's literature, were examined. "Huvava First Environmental Protector" which is the sample of the study, in which text analysis method is used from qualitative research methods, was chosen randomly. It was intended to instill environmental awareness into the minds that are responsible for the world they live in, regardless of age in this book which is considered as "a counter-epic". The word buyrultulamak, which was not found in dictionaries, was evaluated within the scope of neologism. The word buyrultulamak is used not only with the meaning of "to command" as buyurmak but also with the meaning of "to declare as ordered". This word has taken place in children's literature with a fresh creation that does not have to follow the context and shows the originality of the author. Besides it has a rich expressive power that can be a candidate for the dictionary of the standard language. Based on this new word, the place and functionality of neologism in children's literature is discussed.

Keywords: Children's books, Ayla Kutlu, Huvava, neologism, buyrultulamak.

\section{GíRiș}

Çocuğun algı, ilgi, dikkat, duygu, düşünce ve hayal dünyasına uygun; çocuk bakışını ve çocuk gerçekliğini yansitan; ölçüde, dilde, düşüncede ve tiplerde çocuğa göre içeriği yalın biçimde ve içtenlikle gerçekleştiren, çocuğa okuma alışkanlığı kazandırması yanında çocuğun sanat ve estetik yönden gelişmesine katkı sağlayan, çocuğu duyarlı biçimde yetişkinliğe hazırlayan çocuk yazını (Şirin, 2007: 42) ürünleri arasında olan Ayla Kutlu'nun "Huvava İlk Çevre Koruyucusu" adlı eseri, sedir ormanının koruyucu ruhu Huvava'nın doğayı koruma mücadelesini anlatmaktadır.

Gılgamış destanından uyarlanan eserde "İlk Çevre Koruyucusu” olarak adlandırılan Huvava' nın çevreyi yok etmek isteyen, çevreye zarar veren veya zarar vermek isteyenlere karşı mücadelesi bir karşı destan olarak kaleme alınmıştır. Tüm dünyayı ilgilendiren "insan-doğa arasındaki üstünlük savaşı ve doğa tahribatı" ortak sorununa odaklanan yazar, çevre sorunlarına 1şı tutarken insanoğlunun doğa ile ilişkilerini sorgulatmayı hedeflemiştir (Yanık, 2019: 2) Bunu da yazar şu şekilde ifade etmiştir: Insanliğa düşünce ve duygularımı armağan olarak sunmak istiyorum... Yaşlarını göz ardı ederek bütün bilinçli insanlara sunduğum Huvava'nın hikâyesi, bir karşı destan olarak yazdığım çağrı metnidir. Yeryüzünün değerlerini aydınlatan ateş böcekleri gibi, genç kuşakların bellekleri de ışıldasın istiyorum (Kutlu, 2009: 8).

“İlk Çevre Koruyucusu”, "Huvava'nın Hikâyesi”, "Yenilgi” ve "Yeniden Doğuş" olmak üzere dört bölümden oluşan eserin tamamında "insan merkezci" bakış açısının verdiği zararları göstererek insanın çevreye karşı temel sorumlulukları üzerine düşündürüp "doğa merkezci" farkındalık yaratmaya çalışmıştır: Huvava, bilinçli ilk çevre koruyucudur. O nedenle, yeryüzünün elimizden gitmekte olduğu bu günlerde; şimdiye kadar bir simgesi bile bulunmayan koruma eylemleri ve planlar dizgesinin sembolü olarak onun adını ve hayali kimliğini bütün dünyaya öneriyorum (Kutlu, 2009: 7)

Çocuk kitaplarında bazen alışılagelmiş sözcük hazinesinin dışına çıkıldığ1 görülebilir. Genellikle günlük hayatta karşılıklı konuşma esnasında konuşulan konunun bağlamına uygun sözcüğün bellekte bulunmaması ya da bellekten çağrılamaması durumlarında üretilen yeni sözcüklere yazılı anlatımlarda da rastlanabilir. Çocuğun dil beğenisini geliştirmeyi hedefleyen yaklaşımla çocuk kitaplarında bu yeni sözcükler okuyucunun beğenisine sunulabilir.

Yunanca neo "yeni”, logos "sözcük” ile Fransızca akım, kuram, sanat, meslek, görüş gibi adlar türeten -isme sonekinin birleşimiyle meydana gelen neolojizm (Alm. Neologismus, Neubildung; Fr. néologisme; İng. neologism) bir dilin kendi kök ve eklerinden yararlanılarak o 
dilin yaşayan veya ölü sözcüklerindeki yapıya bakılarak yapılan veya ağız ve lehçelerden alınarak kullanıma sokulan "yeni sözcük" anlamına gelmektedir (Karaağaç, 2013:866; Korkmaz, 1992: 172). Kimi kaynaklarda dildeki türetme kurallarına uygun olarak yaratılmış olan bu yeni birimler için yeni öğe (İmer vd., 2011: 270) terimi kullanılmaktadır:

Neolojizm bağlamında değerlendirilen yeni sözcükler belirli bir zaman aralığında yeni sözcüksel (leksikal) bir birim olarak, dilin kurallı yapısı içerisinde sözcük türetme araçları kullanılarak veya yeni olay ve kavramlar için eski leksikal bir birime yeni anlamlar yüklenerek yapılır (Radçenko, 2009: 140 aktaran Şafak, 2018: 7).

\section{YÖNTEM}

Çalışmanın amacı, çocuğun düş dünyasını ve gerçeklik algısını aşmayacak düzeyde olması şartıyla çocuk kitaplarında yer alan yeni sözcüklerin çocuğun sözcük dağarcığına ne gibi katkılar sağlayacağını ortaya koymaktır. Nitel araştırma yöntemlerinden metin analizi yöntemi kullanılan çalışmanın örneklemi Ayla Kutlu'nun "Huvava İlk Çevre Koruyucusu" dur. Bu örneklem, yansız (random) seçilmiştir.

Çalışma konusu olan buyrultulamak sözcügüünün “yeni sözcük” olup olmadığı konusunda Türk Dil Kurumu'nun Büyük Türkçe Sözlük, Güncel Türkçe Sözlük, Türkiye Türkçesi Ağızlar Sözlüğü, Tarama Sözlüğü, tarihi ve çağdaş Türkçe etimoloji sözlüklerine ve Google, Yandex, Yahoo, İnfo, Boardreader, Goodsearch arama motorlarına başvurulmuş ve bu sözcükle ilgili herhangi bir veriye ulaşılamamıştır.

\section{BULGULAR}

Sözlüklerde yer almadığı tespit edilen yeni sözcükler hazır bir listesi olmayan cümleler gibi konuşulan anın bağlamsal gerekliliğinde üretildiklerinden ortaya çıkışları cümle üretimine benzemektedir. Aynı durum veya olay için farklı zamanlarda farklı cümleler üretildiğinden cümle üretiminde sinır yoktur (Herbst, 2012: 118; Katamba, 1993: 65-66).

Var olan sözlüklerde ya da sözcük listelerinde yer almayan sözcükler doğal olarak konuşucuların zihinsel sözlüğünde yer alabilir çünkü tüm sözcükleri içeren kapsayıcılıkta bir sözlüğün varlığından şüphe edilmelidir. Bu sebeple o dile özgü sözcüklerin listesine ilişkin bir sınır çizmek zordur. Sözcükler sözdizimsel kurallar gibi, üretken olduğundan sözcük kök ya da gövdelerine yeni biçimbirimsel yapılar eklenerek yeni biçimler oluşturulabilir (Sebzecioğlu, 2013: 30). Biçimbilimde yeni sözcüklerin oluşumunda üretkenlik önemli bir noktadır ancak bu üretkenliğin de bir çerçevesi vardır. Örneğin tuzlusuz sözcügünün eklerinin sıralanışı ve anlamsal koşutluğu sebebiyle dilbilgisi dışı bir sözcük olduğu açıktır ve konuşucular bu sözcüğü duyar duymaz dilbilgisel yanlışlığı fark edeceklerdir. Yeni sözcükler üretilir üretilmez günlük yaşamda kullanım alanı bulamayabilir, konuşucuların pek tercih etmediği bir biçim olarak kullanımdan düşebilir. Bunun sebebi sadece dilbilgisel kurallar değildir. Kurallara uygun birçok olası sözcük, tuhaf bulunmasından dolayı konuşucular bu yeni sözcükleri kullanmak konusunda isteksiz olabilirler. Yeni sözcüklerin günlük konuşma diline yerleşmesi sözcüğün o dilin konuşucuları tarafından bilinen sözlüksel bir birim haline getirmesiyle başka bir deyişle sözcüğün sıradanlaşmasıyla olmaktadır. Böylelikle sözcükler sözlüğe girmeye aday bir dilsel birim olmaktadır. Yani sadece konuşucunun zihinsel sözlükçesinde yer alan sözcük sözlük içinde de yer alarak hem biçimsel hem de anlamsal olarak daha belirginleşmiş olduğunu 
kanıtlamakta ve sözlükselleşen sözcük, hem anlam hem de biçim olarak oluşum sürecini tamamlamaktadır (Sebzecioğlu, 2013: 24).

buyur-ul-tu+la- yapısının sözlüklerde yer alan en küçük birimi olan buyur- eyleminin anlamı Büyük Türkçe Sözlük'te "Bir şeyin yapılmasını veya yapılmamasını kesin olarak söylemek, emretmek. 2. Söylemek, demek, düşüncesini bildirmek. 3. Gelmek, gitmek, geçmek, girmek 4. Almak. 5. Etmek, eylemek (yardımcı eylem)" anlamları verilmiştir (https://sozluk.gov.tr/). Bilinen en eski Türkçe metinlerinden ${ }^{1}$ pek az şekil değişikliği göstererek günümüze kadar gelen sözcük, günlük dilde genellikle 1. anlamıyla işlek olarak kullanılmaktadır.

Eylemin özne ve nesne ilişkisi bakımından görev ve anlamca tamamlanmasını sağlayan - $l$ - eki, yaygın olarak kılış fiilleri üzerine gelerek edilgen çatı işlevi için kullanılmaktadır². "Buyurma işine konu olmak" anlamıyla buy $(u) r-u l$ - biçimi biçimbilimsel kural yönetimli olarak Türkçedeki hemen hemen bütün eylemlerde görülebilen örnekseme ile türetilmiştir. Herhangi bir özneye gerek duymayan buyrul- edilgen çatılı tabana "-tu" eylemden ad türeten birim eklendiğinde ortaya çıkan buyrultu biçimi "sadrazam, vezir, beylerbeyi gibi yüksek devlet görevlileri tarafından yazılan buyruk (Güncel Türkçe Sözlük, 2011), belge, diploma, davetiye (Derleme Sözlüğü C2, 2009: 808).” anlamlarıyla metinlerde işlek bir kullanım sergilemiştir. Türkçe Sözlük'te yer alan buyrultu biçimi, bu bağlamda, "karışmaz iki sıvıdan birinin öbürünün içinde çok küçük damlacıklar halinde asılı kaldığı incelmiş karışım" anlamındaki asıltı gibi biçimbilimsel kurallara uygun türetimlere örnek gösterilebilir.

Türetim ekinin eklendiği taban, $-l-,-n$ - eklerinin eylemlere gelmesi gibi, ekin doğal olarak eklenebildiği sözcük türüne uygun olması gerekir. Böylece yeni oluşturulan biçim Türkçenin beklendik biçimbilimsel kurallarına uymuş olur. Yeni sözcükler bazen tabanlara kural dış1 gelen türetim ekleri ile oluşturulduğundan bu yeni sözcükler ölçünlü dil açısından dilbilgisidışı olarak değerlendirilir. Türetimlerde ekin sözcüğün işlevine de uygun olması gerekmektedir çünkü bazı durumlarda ekin geldiği taban, ölçünlü dildeki türetimlere uygun olsa da ekin işleviyle anlamı arasında bir karşıtlık oluşur (Sebzecioğlu, 2013: 30- 31). Bu gibi türetimler çocuk yazınında çocuğun dil gelişimini olumsuz etkileyebilir. Söz konusu buy(u)r-ul-tu+labiçiminde ilk bakışta sözcüğe eklenen eklerin alışılmadık ya da fazladan olduğu düşünülebilir ancak bu yapı ölçünlü dilde kullanılan ve tamamen dilbilgisel olarak nitelendirilen alıntıla-, ilintile-, görüntüle- eylemleriyle aynı yapısal özellikleri göstermektedir.

Türetilen bazı yeni sözcükler metin bağlamlı olup metin dışında kullanışsız olabilmektedir. Ancak "Huvava İlk Çevre Koruyucusu" eserinde: "Dağlar dışında şöyle buyrultuladı: Onun gibi davranma. Sen iyiler iyisisin, Sen barış ve dostluksun. Sen anlatmazsan kim anlatabilir o canavara? Söyle, Huvava!'(Kutlu, 2009: 16) cümlelerinde buyrultulamak eylemi bağlama bağ li kalmamış, bağlam dışında da eylemin anlamı açıktır. Başka bir deyişle buyrultulamak tek başına kullanıldığında anlamda herhangi bir belirsizlik söz konusu değildir.

\section{SONUÇLAR VE TARTIŞMA}

Erken çocukluk döneminden başlayıp ergenlik dönemini de kapsayan bir yaşam evresinde, çocukların dil gelişimi ve anlama düzeylerine uygun olarak duygu ve düşünce dünyalarını,

\footnotetext{
${ }^{1}$ buyruk "kumandan" < buyur- "buyurmak, emretmek" (Kül Tigin Yazıtı, Güney Yüzü, 1. Satır) Divanü Lûgat-it-Türk I 186, 353- 425; II 214, 346; III 123, 297.

${ }^{2}$ Ayrıntılı bilgi için bakınız: Delice, 2007.
} 
sanatsal niteliği olan dilsel ve görsel iletilerle zenginleştiren, beğeni düzeylerini yükselten çocuk kitapları (Sever, 2007: 9) sadece biçimsel özellikleriyle değil; teması, konusu, olay örgüsü, kurgusu, dil ve anlatımları ile çocuğun yaş düzeyine uygun bir şekilde çocuklara sunulmaktadir.

Dilin zengin anlatım olanaklarını hissettirmeyi hedefleyen çocuk kitaplarında yeni türetimler çocukların beğenisine sunulabilir. Çocukların alıcı ve ifade edici dil gelişimlerini destekleyen bu tür türetimlerde dilde var olan bir tabandan yeni bir sözcük oluşturma süreci vardır ancak bazı eserlerde yeni türetilen biçim, birkaç bağlamsal koşul farklılığı dışında sözcük kök ve gövdesinden çok farklı bir anlam ifade etmemektedir. Ancak incelenen eserde tespit edilen buyultulamak sözcüğü buyurmak gibi sadece "emretmek" anlamiyla değil, "kendisine buyrulduğu üzere bildirmek" anlamıyla, yazarın özgünlüğünü gösteren taze bir yaratımla çocuk yazınında yer almıştır.

Buyrultulamak sözcüğünün aynı anlamı verebilecek olan sözcüklerin sözlükçeden getirilememesinden değil; taze bir türetimle anlamda yapılmak istenen farklılığ ortaya koymak için kullanıldığ 1 düşünülmektedir. Farklılık yaratma ile beklenen çocuğun zihnindeki dikkat sürecini harekete geçirmek veya ayakta tutmaktır.

Sözcügün biçim ile anlam arasındaki tahmin edilebilirlik düzeyine bakıldığında çocuk kitabında yer alması itibariyle sözcügün tam olarak bağlama bağımlı olduğu söylenememektedir. Sözcügün anlamı bağlam içerisinde daha da netlik kazanmasıyla birlikte üretildiği dilsel ortama bağımlı değildir.

Bazı durumlarda, yazarın dili ustaca kullanımlarından doğan bu biçimler; edebî eseri daha başarılı, okuyucu nazarında daha etkili kılmak, yazarın kurgusunu, fikir ve hislerini kendisine has bir üslupla anlatmak için ihtiyaç duyduğu yeni sözcüklerdir (Şafak, 2018: 29). Bir karşıt destan olarak yazılan eserin epik söylemine uygun bir türetim olan buyrultulamak eylemi yazarın özgün üslubunun bir meyvesi olarak yorumlanabilir.

Yazarın deyimiyle bir "çağrı metni” özelliği gösteren eleştirel destanın mitolojik söylemine uygun olarak, rastlantısal değil; bilinçli bir tercihle türetilen buyrultulamak eylemi, ölçünlü dilin sözlüğüne aday olabilecek niteliğge ve zengin bir ifade gücüne sahiptir.

Çocuğun düş dünyasını ve gerçeklik algısını aşmayacak düzeyde olması şartıyla çocuk kitaplarında yer alacak yeni sözcükler; dili renklendirmeye yarayan bir çeşni gibi (Bachielli, 2010) çocuğun sözcük dağarcığını zenginleştirir, dili etkin ve doğru bir şekilde kullanmasına katkıda bulunulur.

\section{Etik Metin}

$\mathrm{Bu}$ makalede araştırma ve yayın etiği kuralları takip edilmektedir. Makale ile ilgili her türlü ihlalin sorumluluğu yazar/yazarlara aittir.

\section{KAYNAKÇA}

Atalay, B. (1999). Divanü lûgat-it-Türk dizini “endeks”. Türk Dil Kurumu Yayınlar1.

Bachielli, R. (2010). Our worries about 'nonce' (Something more than a terminological problem). Linguae \& Rivista di Lingue e Culture Moderne, (2010), 83-90. 
Delice, H.İ. (2007, Eylül 10-15). Çatı eklerinin bilinmeyen bir işlevi [Sözlü sunum]. Atatürk Kültür, Dil ve Tarih Yüksek Kurumu 38. Uluslararası Asya ve Kuzey Afrika Çalışmaları Kongresi (ICANAS 38), Ankara, Türkiye.

Türk Dil Kurumu, (2011). Güncel Türkçe Sözlük. Türk Dil Kurumu Yayınları.

Herbst, T. (2010). English linguistics (A coursebook for students of English). Mouton de Gruyter.

İmer, K., Kocaman, A. \& Özsoy, A. S. (2011). Dilbilim sözlüğü. Boğaziçi Üniversitesi Yayınevi.

Karaağaç, G. (2013). Dil bilimi terimleri sözlüğü. Türk Dil Kurumu Yayınları.

Katamba, F. (1993). Morphology. Mcmillan.

Korkmaz, Z. (1992). Gramer terimleri sözlüğ̈̈. Türk Dil Kurumu Yayınlar1.

Kutlu, A. (2009). Huvava İlk Çevre Koruyucusu. Bilgi Yayınevi.

Radçenko, M. (2009). Slovobrazitelnıye neologizma v sovremennam Rusko iHırvatskom yazika. Vesnik Volgograd, (30). 140-144.

Sebzecioğlu, T. (2013). Anlık oluşum ve Türkçe anlık sözcüklerin oluşum süreçleri üzerine bir betimleme. Mersin Üniversitesi Dil ve Edebiyat Dergisi,10(1), 11-4.

Sever, S. (2007). Çocuk ve edebiyat. Kök Yayıncılık.

Şafak, Z. (2018). Fransızca ve Türkçede akıllı telefon bağlamında yeni sözcük kullanımına (neolojizm) yapısal bir yaklaşım [Yayımlanmamış yüksek lisans tezi]. Tekirdağ Namık Kemal Üniversitesi, Sosyal Bilimler Enstitüsü, Tekirdağ, Türkiye.

Şirin, M. R. (2007). Çocuk edebiyatı kültürü. Kök Yayıncılık.

Tekin, T. (1998). Orhon yazıtlarl (Kül Tigin, Bilge Kăgan, Tunyukuk). Simurg.

Yanık, Z. (2019). Ayla Kutlu'nun çocuk kitaplarının çocuk edebiyatı açısından değerlendirilmesi [Yayımlanmamış yüksek lisans tezi]. Ordu Üniversitesi, Sosyal Bilimler Enstitüsü, Ordu, Türkiye.

\section{Internet Kaynaklart}

https://sozluk.gov.tr/ 


\section{EXTEND ABSTRACT}

\section{An Example of Neologism in Children's Books: Buyrultulamak}

Children's books are one of the most effective tools in language learning, which contains the cognitive area in which behaviors dominated by mental activities are coded. The importance of books is undeniable in children's mental activities to understand the world and the events around them, in the process of comparing stimuli perceived from the external environment with previous information and creating new information. They are the first books that come to mind in the acquisition of concepts such as emotions, preferences, values, moral rules, wishes, motives and orientations that are desired to be gained by human beings, which are within the scope of the affective behaviors. In order to reveal the use of new words or phrases in children's books and the contribution of this usege to the language development of children, in this study, the vocabulary elements of Ayla Kutlu's "Huvava First Environment Protector", a product of children's literature, were examined. "Huvava First Environmental Protector" which is the sample of the study, in which text analysis method is used from qualitative research methods, was chosen randomly. It was intended to instill environmental awareness into the minds that are responsible for the world they live in, regardless of age in this book which is considered as "a counter-epic". The aim of the study is to reveal how the new words in children's books will contribute to the child's vocabulary, provided that they do not exceed the child's dream world and perception of reality. Regarding whether the word "buyrultulamak", which is the subject of the study, as a "new word", Turkish Language Institution's Big Turkish Dictionary, Current Turkish Dictionary, Turkey Turkish Dialects Dictionary, historical and contemporary Turkish etymology dictionaries; Google, Yandex, Yahoo, Info, Boardreader, Goodsearch search engines were consulted and no data could be found about this word. Buyrultulamak is used not only with the meaning of "to command" as buyurmak but also with the meaning of "to declare as ordered". This word has taken place in children's literature with a fresh creation that does not have to follow the context and shows the originality of the author. Also, new derivations showing the power of rich expression possibilities of language can be presented to children's taste in children's books. Besides, it has a rich expressive power that can be a candidate for the dictionary of the standard language. Based on this new word, the place and functionality of neologism in children's literature is discussed.

\section{(ब) $(\Theta \odot$}

"International Journal of New Approaches in Social Studies - IJONASS" is licensed under a Creative Commons Attribution-NonCommercial-ShareAlike 4.0 International License. 